\title{
BRINGING CLEAN ENERGY TO THE BASE OF THE PYRAMID THE INTERPLAY OF BUSINESS MODELS, TECHNOLOGY, AND LOCAL CONTEXT
}

\author{
EMILY ALBI \\ Santa Clara University \\ Santa Clara, California, U.S.A. \\ ealbi@scu.edu
}

\author{
ANDREW E. LIEBERMAN \\ (corresponding author) \\ Santa Clara University \\ Santa Clara, California, U.S.A. \\ alieberman@scu.edu
}

\begin{abstract}
Social enterprises are providing affordable energy and environmentally sustainable energy to a small but growing percentage of the four billion people living on less than $\$ 2,000 /$ year. Santa Clara University's Global Social Benefit Incubator (GSBITM) has worked with over 60 of these enterprises and profiled them on its Energy Map website. Based on this direct experience and associated research, the authors conclude that it is the interplay among innovative business models, quality technologies tailored to localized energy markets, and appropriate interfacing with local ecosystems that allows social enterprises to go to scale. This conclusion is supported by a review of prominent enterprises including Shindulai, Solar Sister, Angaza Design, Potential Energy, Selco, Husk Power Systems, and Practical Action.
\end{abstract}

Acknowledgements. The authors wish to thank Applied Materials for their financial support of the Energy Map and the preparation of this article as part of the Collaborative on Clean Energy for the Underserved. 


\section{INTRODUCTION}

As Koch and Hammond (2013) describe in the preceding article of this special issue, nearly half the world's population is living in energy poverty, defined as a lack of household access to electricity or the absence of a cooking stove that does not cause air pollution in houses (International Energy Agency, 2013). The effects of energy poverty are far-reaching, prompting UN Secretary-General Ban Ki-Moon to state that "without access to energy, it is not possible to achieve [the Millennium Development Goals]" (Ki-Moon, 2011). Economically, those who suffer from energy poverty fall within the "Base of the Pyramid" (BoP), which is defined as the four billion people living on less than \$2,000/year (Prahalad \& Hammond, 2002). Ironically, although they are the people on the planet with the least amount of disposable income, they are spending $\$ 500$ billion annually on energy, primarily on inferior products such as kerosene lamps (Hystra, 2009). Clearly, a major development challenge is how to provide affordable and environmentally sustainable energy to the BoP.

Governments will not be able to provide sufficient energy to the BoP by simply building more coal-fired plants, distributing diesel generators, or subsidizing kerosene and liquefied petroleum gas, all of which are costly and contribute to environmental degradation. It appears more viable to bring distributed clean energy technologies to the BoP that will meet their energy needs, promote development, and protect the environment. This article seeks to add to the emerging dialogue regarding best practices in the provision of distributed energy to BoP communities, highlighting success factors from social enterprises that have participated in Santa Clara University's Global Social Benefit Incubator (GSBI ${ }^{\mathrm{TM}}$ ). GSBI is an intensive capacity development program specifically designed to help social entrepreneurs achieve financial sustainability and create systematic change. Based on the experience of working with these social enterprises and on associated institutional research, three overall success factors can be distilled. These three factors are:

- Appropriate technologies

- Innovative business models

- Integration with local context

It is the interplay among innovative business models, quality technologies tailored to localized energy markets, and appropriate interfacing with local ecosystems that allows social enterprises to go to scale. 


\section{SECTION I: BOP ENERGY LANDSCAPE}

To understand these success factors across such a broad segment of the world's population, it is necessary to consider the landscape of current lighting needs and solutions, other electricity-based needs, and for cooking as well.

Electrical grids in BoP regions are commonly unreliable, providing intermittent and unpredictable power. It is estimated that only $30 \%$ of households in Sub-Saharan Africa have a grid connection, and of those, a third receives only intermittent power, largely because large-scale power production is insufficient to respond to peak demand (Practical Action, 2012).

In the Nepalese communities of Hatiya and Handikhola, more than $80 \%$ of households surveyed for the Poor People's Energy Outlook report had a grid connection, yet all of them received intermittent or poor quality power (Practical Action, 2012). This situation exists because grid electricity in Nepal derives its power from hydro-electric plants which suffer long power cuts in the dry season (Practical Action, 2012). The seasonal situation in Nepal is a microcosm of the wider reality of grid power in developing countries. Contributing factors include "technical issues, which can include insufficient generation capacity and aging equipment, as well as socio-economic and institutional issues such as insufficient management and maintenance capacity" (Practical Action, 2012).

In India, a different seasonal problem exists. Each state controls its own supply of electricity and chooses how to distribute it among urban and rural areas. More prosperous and better-managed states such as Gujarat produce enough energy to consistently meet their needs and regularly sell surplus power to neighboring states. Other states fall short to varying degrees. One example of an energy poor state is West Bengal, which prioritizes providing electricity to meet the needs of its major city, Kolkata. In the cool season, there is sufficient power to meet Kolkata's needs and to provide a reliable supply to neighboring grid-connected villages. In the hot season, however, energy demand in Kolkata increases due to the use of air conditioning systems, refrigeration, and increased water demand. The increased demand leads to daily energy cuts in the villages, and precisely during peak hours when they also need electricity the most (Alok Piri, personal communication, 1/23/13). 
For these reasons, the International Energy Agency (2010) estimates that by $2030,100 \%$ of urban-but only $30 \%$ of rural-households will be connected to grid electricity. Social enterprises target the remaining market of $70 \%$ of rural households. Although conventional energy technologies are continually improved and refined, the developing world has a unique set of requirements that are not met by technologies designed for the developed world. Appropriate technologies, not necessarily new ones, are crucial for bringing clean energy to the BoP. The IEA expects that energy demand will be met by an increasing use of mini-grid or other types of distributed systems.

BoP consumers have four key needs that can be addressed through electricity availability: lighting, mobile phone charging, entertainment, and other income-generating uses. While a reliable grid connection enables consumers to fulfill all of these needs, there are alternative solutions that are popular where the grid is non-existent or unreliable. These traditional alternatives, however, frequently have negative health, environmental, and economic consequences for their users.

Just as humans have done since the invention of fire, BoP consumers seek to extend their productive day through lighting which enables them to work longer hours, do household tasks, and study. In off-grid BoP communities, this need is commonly met by kerosene lamps. Worldwide kerosene consumption is estimated to be equivalent to 440 billion barrels of oil per year. This level of consumption translates into 190 million tons of $\mathrm{CO}_{2}$ released into the atmosphere per year, the same amount of $\mathrm{CO}_{2}$ that 30 million cars release in the same amount of time (Hystra, 2009). Moreover, in addition to toxic fumes from kerosene lamps, the danger of fire and ensuing risk to life and property is substantial. In India alone, 2.5 million people every year suffer severe burns due to overturned kerosene lamps (the health implications of fuel-based lighting "are two-fold: chronic illness due to indoor air pollution and risk of injury due to the flammable nature of the fuels used") (Lighting Africa, 2010). Cleaner lighting contributes to easing such effects while yielding significant cost savings to consumers in the BoP. Although solar lights have an upfront cost ranging from $\$ 11$ to $\$ 65$, the kerosene savings lead to a payback period from eight to as little as two months for the average consumer, depending on distribution economics and market potential (Lighting Africa, 2010).

Mobile phones have become a central communication and financial tool for people in the BoP. It is expected that the number of mobile phone subscriptions will surpass the world's population by 2014 (Mlot, 2012). World Bank Vice President for Sustainable Development Rachel 
Kyte describes the potential of this revolution for the BoP: "mobile communications offer major opportunities to advance human and economic development-from providing basic access to health information to making cash payments, spurring job creation and stimulating citizen involvement in democratic processes" (World Bank, 2012). However, since mobile phone coverage surpasses electrical grid coverage, there is a growing demand for off-grid mobile charging options (Lighting Africa, 2010). In Kenya, for example, $20 \%$ of the population have access to the grid or off-grid electricity, but $42 \%$ have mobile phone subscriptions, leaving off-grid mobile phone users to pay from $\$ 0.10$ to $\$ 3.00$ per cell phone charge, creating a $\$ 155$ million phone charging industry in Kenya alone (Lighting Africa, 2010). In addition to the economic cost, consumers also suffer the costs in lost time and travel to get to a phone charging kiosk.

In addition to being a communication and financial tool, mobile phones are quickly becoming a major entertainment device in the BoP, complementing or supplementing TVs and radios. It is becoming clear that the owners of mobile phone charging kiosks and other micro-entrepreneurs earn significant revenue streams from downloading music and games to customers' mobile phones. This added usage will also cause BoP users to recharge their phones more frequently than they would if they were using their phones only for calls (Paul Meissner, personal communication, 3/13/13).

The largest energy use in the BoP, however, is not lighting, charging, or entertainment. Cooking requires more energy, but there are severe environmental, health, gender, safety, and economic consequences to using traditional cooking methods in the BoP. With regard to the environment, traditional cooking practices can degrade land and cause local and regional air pollution (International Energy Agency, 2006). It is estimated that 1.6 million people die every year due to indoor air pollution from cooking indoors with firewood, dung, and refuse (Hystra 2009). Moreover, women and girls in developing countries overwhelmingly bear the burdens of cooking the family's meal as well as collecting the necessary fuel. Completing these tasks can mean 20 or more hours per week spent on "long, exhausting walks in dangerous or isolated areas" to collect fuel for cooking. In war-torn areas, these isolated walks often make a woman highly vulnerable to rape. In addition to the gender issue these walks create, the lost productivity occasioned by the need to search for sources of fuel and to collect it can ruin a woman's chances of economic gain: "time spent collecting fuel often leaves less time to work in the fields, start a small business, or engage in other pursuits that can bring much needed money into the household" (Global Alliance for Clean Cookstoves, 2011). 
There is thus a clear link between improved access to energy and improved economic opportunities. Practical Action, in their 2012 report, identified three mechanisms through which energy access relates to earning a living: (1) creating new earning opportunities, (2) improving existing earning activities, and (3) reducing opportunity costs. With access to energy, new earning opportunities for enterprises such as mobile charging kiosks can be realized. Existing earning activities (weaving products at home for sale, for example) can be improved with lighting by allowing for longer hours, lowering costs, and improving the quality of the goods produced. Access to energy reduces opportunity costs by allowing more time to be spent on economic endeavors. Women and girls who invest hours each day searching for wood and other cooking fuels could instead spend that time on school work, or on other incomegenerating activities (Practical Action, 2012).

In this article, we analyze how social entrepreneurs are addressing the energy needs of the BoP by examining each of the three success factorstechnology, business model, and local context. Each factor is illustrated with a brief case study that provides anecdotal evidence of how these factors influence energy poverty elimination efforts in BoP communities.

Santa Clara University's Energy Map profiles over 60 social enterprises working around the world to bring clean energy to the BoP (energymapscu.org/about). The social enterprises are largely graduates of the GSBI program. Along with profiles of these energy-focused social enterprises, the Energy Map outlines technologies and business models that have been successfully implemented by them.

\section{SECTION II: APPROPRIATE TECHNOLOGIES}

The most common power sources used in the BoP can be grouped into biomass, solar, and a smattering of other renewables like wind and hydro (energymap-scu.org/technologies/power-sources). Using these power sources, social enterprises offer such products as lanterns, home lighting and electrical systems, cookstoves, and mini-grids (energymapscu.org/technologies/products).

Design considerations for different markets vary substantially. For example, Shidhulai, a social enterprise working in flood-prone Bangladesh, knows that their customers would not consider a home system that was not portable, so they sell lighting systems that people can take with them upon evacuating their homes. In other geographies, such as densely populated Indian villages, smaller, decentralized versions of 
conventional grids—such as mini-grids or micro-grids—offer lower costs through better efficiency and scalability, but introduce other complexities, including the need to prevent energy theft. In less densely populated villages, such as those found in rural Africa, individual home systems are more cost-effective (energymap-scu.org/technologies/power-uses/ off-grid-lighting-and-electricity/community-level-power).

Demand for energy technologies is not limited to those people entirely off the grid. Interestingly, the inexpensive grid costs do not always attract the poorest of the poor. Researchers are finding that, at least up to a certain point, the BoP market values reliability over cost:

\begin{abstract}
The presumably less expensive (and heavily regulated) [grid] costs [...] do not necessarily induce customers to voluntarily buy the regulated networkand despite government programs to "help poor people" by setting low prices-customers turn to more expensive but reliable alternatives. [...] Many countries have by now experienced the effects of energy development projects that did not adequately consider reliability in the design of operational systems. (Ballonoff, 2013)
\end{abstract}

Although poor, consumers in India and the rest of the BoP do not base their purchasing decisions on price alone. Guillermo Wille, former Managing Director at GE India, relates: "the beauty of the Indian market is that it pushes you in a corner ... it demands everything in the world, but cheaper and smaller" (Kumar \& Puranam, 2012). Such consumer demand and the large market size foster a "leapfrog technology" pattern in developing countries where infrastructure gaps have "positively affected Indian innovation" (Kumar \& Puranam, 2012). This leapfrogging is being achieved through frugal innovation, which encompasses designing for affordability, ruggedization, adaptation, green technologies, use of local resources, simple user-centric design, weight, and "magnificent" simplification (scu.edu/engineering/frugal). These factors are all relevant, though perhaps user-centric design is most important to this discussion. User-centric design incorporates attributes that target users value most.

Lighting Africa's 2010 "Solar Lighting for the Base of the Pyramid" report documents the "trend toward consumer-oriented design." Six primary factors are relevant for lighting in rural markets: (1) multiple recharge options, (2) multiple dimming settings and battery life notification, (3) mounting features, (4) durability, (5) modular design, and (6) mobile phone recharge options. The report notes how the market for solar portable lights has shifted-from one driven by NGOs primarily seeking tools to support development-to one driven more by evolving consumer demand: 


\begin{abstract}
Social entrepreneurs along with pure profit driven ventures have begun to respond to the choice of the customer and offered designs and features which better align with customer demands. [...] While lanterns fill a basic consumer desire for light, value added features increase the range of product offerings within this segment. Many of these features help to reduce the upfront costs or increase overall economic benefit to the customer, thereby increasing demand and expanding the market.
\end{abstract}

Not only does the technology have to be high quality, but it also needs to have the right features. The market trends reported in Lighting Africa are consistent with the trends seen in the work of the social enterprises that have gone through GSBI. Increasingly, mobile phone charging capability is the must-have feature for BoP consumers (World Bank, 2012). If a BoP family is going to invest a week or a month's income in an energy product, the family must perceive that it will receive sufficient return, which could include economic benefits through savings in kerosene or fuel wood, increased productivity by being able to work more hours, and aspirational advantages through improved status in the community.

Angaza Design, a GSBI 2011 graduate, focuses on user-centric design for clean energy in rural Eastern Africa. Angaza strives to "integrate engineering solutions with first-hand field experience" by "combining human-centered design with innovative technology to reshape the global energy market" (www.angazadesign.com). The social enterprise designs solar technology that it distributes through partners. Angaza's technology solution is the SoLite3 Solar Home System, a system that contains an LED light unit, a detached photovoltaic (PV) panel, and a pay-as-you-go control unit. The system has a run time of eight hours on its low setting and four on its high one at two watts of power. Multiple brightness settings, a detachable panel, and the output wattage are all specifications that are tailored precisely to rural Eastern Africa where Angaza is doing business. These specifications are based on extensive research and, more importantly, ongoing feedback from customers.

There are also constraining and driving factors for adoption of clean cookstoves. As a "push" product, cookstoves are difficult to sell because they replace wood and refuse-based cooking which have long histories of use, and whose fuels are perceived as free because women's time is not valued. On the other hand, a "pull" product like the Internet provides a new service that does not replace well-entrenched comparable practices (Global Alliance for Clean Cookstoves, 2011). To make a cookstove desirable, it must conform to a number of user-centric design specifications, including not altering the taste of food, providing the ability to regulate temperature easily, cooking food quickly, and reducing the cost of, or time spent collecting, fuel (Global Alliance for Clean Cookstoves, 
2011). Given the enormous variation among BoP markets, a multiplicity of cookstove solutions is needed to meet the specific needs of different communities. One successful cookstove entrepreneur is Potential Energy, whose "5-Minute Stove" has proven popular with customers in Sudan and Ethiopia. The stove name and slogan of "Don't burn your money, buy the 5-minute stove" were created in the Potential Energy team together with early customers in Sudan. Key advantages over traditional three-stone fires are that it uses only $1 / 4$ the firewood, and cooks food in just $1 / 10$ of the time. Part of what enabled such drastic reductions is a design optimized for the traditional pots and meals in each target country (scu.edu/socialbenefit/resources/library.cfm?id=001A000000eEELz).

Thus, the challenge for social entrepreneurs who wish to develop successful energy products for the BoP is not to reinvent clean energy technology, but rather to adapt existing technologies to the specific communities they intend to serve.

\section{SECTION III: INNOVATIVE BUSINESS MODELS}

Along with tailored technology, an innovative business model is a necessary success factor to scale social businesses in the BoP. Jim Koch, founder of Santa Clara University's Center for Science, Technology, and Society and former Dean of the Leavey School of Business, explains the framework for success in social entrepreneurship:

\footnotetext{
Schumpeter's concept of entrepreneurship as combinatory innovation is evidenced across social entrepreneurs in the Energy Map .... Their efforts must simultaneously attend to localizing technology, establishing business models for the creation of "new markets," and interfacing with local ecosystems through alliances and novel value chain innovations. (James Koch, personal communication, 1/16/13)
}

Even with a high-quality and frugally-engineered product adapted to the local context, the potential for high impact at the BoP can only be realized with an effective business model. The BoP business model challenge is the same as the technology challenge: finding what works.

Social enterprise business models must respond to the stiff hurdles at the BoP in the local context of the communities they serve. Business models can be categorized by six parameters: (1) product sourcing and design, (2) distribution, (3) affordability, (4) organization financing, (5) scaling, and (6) social impact (energymap-scu.org/business-models). 
Perhaps the most salient business model parameter for device-oriented enterprises is distribution, which "has emerged as the major determiner of commercial success in selling modern energy solutions to underserved households" (International Finance Corporation, 2012). In rural markets, distribution means reaching villages far removed from transportation infrastructure, and doing so profitably. Companies that are successful in last-mile distribution possess a valuable core competency that distinguishes them from potential competitors.

Consumer financing is another important parameter in BoP business models - it makes products affordable over time for BoP customers. SELCO, founded in 1995, has sold, serviced, and financed over 135,000 solar systems in 5 states in India (www.selco-india.com). It is described by the Yale School of Management as "one part customized technology ... one part customized finance" for its aggressive efforts to make its solar home lighting and electricity systems available to rural households through microfinancing (Yale School of Management, 2010). Providing financing to customers and/or suppliers is an essential element of a successful BoP energy venture business model (Koch \& Hammond, 2013). Distribution and finance, and the remaining four parameters, are hallmarks of business ventures poised to scale in the "stress test" of the BoP marketplace.

Each social enterprise working at the BoP approaches these six parameters in a unique way, tailored to the location and the culture where the social enterprise intends to do business. For example, Avani works in the Indian Himalayas, where firewood is scarce and pine needles are a fire hazard and inhibitor to agriculture. Avani has developed a system for gasifying pine needles to generate power for village use and sale to the state-owned energy grid (energymap-scu.org/avani). In comparison, CCF BushBlok clears invasive brushwood from cheetah habitats in Namibia. The brushwood is processed into fuel logs, which are sold as consumer products in urban areas in Namibia and exported to South Africa and the United Kingdom. Thus, both organizations clear invasive biomass and turn it into energy, but their business models differ significantly due to differences in the local context. In Avani's case, selling electricity to the state-run grid was a logical option because a legal mechanism, called a feed-in tariff, was readily accessible. For BushBlok, fuel logs were identified as a business opportunity that would also create jobs for Namibians and encourage other industries to use bush wood as raw material (www. bushblok.com/project.htm).

Solar Sister, a social enterprise working primarily in Uganda, focuses solely on last-mile distribution. Solar Sister has an Avon-style network of consignment sales agents that almost exclusively employs women. This enterprise is structured in a clean, simple way: a country director man- 
ages a team of regional coordinators spread out among the regions they serve. Each regional coordinator recruits and trains primarily female entrepreneurs. With support from her regional coordinator, an entrepreneur sells a portfolio of solar products. Solar Sister is product agnostic: the company does not design or manufacture any products and is driven by customer demand. Solar Sister carries products designed and manufactured by partner social enterprises, including Angaza Design, d.light Design, Barefoot Power, and Greenlight Planet. From experience working in the field, Solar Sister continually adjusts its business model and tweaks its distribution strategy (www.solarsister.com). Katherine Lucey, CEO of Solar Sister, describes how she arrived at her current business model:

\begin{abstract}
In sub-Saharan Africa, where only $5 \%$ of the rural population has access to electricity, solar is the perfect energy source. The puzzle then becomes: How to provide access to the solar technology in a way that reaches the people with the most need, the women and girls living in remote rural villages? How to create a program that is scalable and sustainable? How to involve the women, not just as passive consumers of technology but as active participants in the adaptation of that technology? I found the answers to those questions by talking to and really listening to the women living with energy poverty day in and day out. (www.solarsister.com)
\end{abstract}

To render business models practical in difficult local markets, CEOs of companies like Solar Sister must learn the specific needs of their consumers. For Solar Sister, an Avon-style distribution model works well. Lucey's description of how she chose Avon-style distribution by talking with "the women living with energy poverty day in and day out" exemplifies this learning. Adapting business models to work among the poorest of the poor takes innovation and ingenuity. Sometimes a simple, classic business model can be the most effective.

\title{
SECTION IV: INTEGRATION WITH LOCAL CONTEXT
}

The third critical factor in serving BoP markets is interfacing with local ecosystems. This factor can be conceptualized as "developing mechanisms to embed the technology and business model into the (underserved) community" (Jain \& Koch, 2009). Institutional voids and severe resource constraints at the BoP require social enterprises to integrate their businesses into local ecosystems to deliver goods and services. Integration can be accomplished in a variety of ways. Four factors are central to successful interfaces: (1) building domain legitimacy among external stakeholders, (2) establishing credibility within the community, (3) be- 
coming involved with the community, and (4) crafting a relationship with the government (Jain \& Koch, 2009).

Building domain legitimacy among external stakeholders, which is necessary for obtaining investment capital and partnerships, requires the social enterprise to show that its products or services have social benefit and that the enterprise has a business model that will enable continued growth. Winning prestigious awards and competitions has become a useful tool for legitimizing social enterprises in the eyes of external stakeholders with limited knowledge of the specifics of a given technology or the local context in which it is being deployed (Jain \& Koch, 2009). The social enterprises cited in this article have received awards and recognition from notable sources, including The Tech Awards, Fast Company, BBC World Challenge Competition, and Clinton Global Initiative.

Credibility within the community is of equal importance because it leads to user adoption. Building credibility entails educating consumers about the benefits of a given product, which is accomplished by using local sales agents. It also entails working to counter negative stereotypes that remain from unreliable companies or government programs. That problem has been worsened by the growing number of profit-first companies selling low-quality solar lanterns to the BoP. These products have frequent performance and durability issues which spoil the market for distributors of quality products (Lighting Africa, 2010). In villages, customers talk to each other and will give either positive or negative references to a given technology. Because of these factors, Solar Sister offers its sales agents a variety of vetted products, but also recognizes that different communities will prefer one product over another, noting that "often customers from a community will prefer one product because everyone else in that community has chosen it" (energymap-scu.org/solar-sister).

To establish trust at a community level, social enterprises may need to partner with non-governmental organizations (NGOs) and local governing bodies. With an integrated network that encompasses "not-for-profits, corporates, public sector, government" and essentially everyone else, social problems become more realistic to solve (Stevens, 2012). A strong alliance can work to strengthen business necessities such as distribution (i.e., by partnering with businesses that have "already established strong channels" [International Finance Corporation, 2012]). Non-profit social enterprises often build their models on this type of community-level engagement because they have existing relationships with village-level NGOs and other community groups. This approach is being followed successfully by CTxGreEn, which works with Indian self-help groups to produce biodiesel water pumps. Producing the pumps enables new forms of agricultural productivity while providing additional livelihood oppor- 
tunities through jobs related to producing the biodiesel and managing the pump (energymap-scu.org/ctx-green).

The fourth factor is crafting the appropriate relationship with the government. This step often means accessing government subsidies for clean energy solutions and rural development. Practical Action Peru has made the creation of community-scale micro-hydro power plants affordable for rural communities by partnering with the government on the installation of each plant. In their model, the government subsidizes most of the installation costs and retains ownership of the plant, but it is administered by a community group formed by Practical Action that collects monthly payments from the beneficiaries and is responsible for operations and maintenance (energymap-scu.org/practical-action-peru).

Husk Power Systems (HPS) provides an example of a social enterprise with an appropriate technology and an innovative business model that has addressed all of these local context factors. HPS was first conceived by two men looking for a way to give back to the people of Bihar, their home state in India. Gyanesh Pandey and Ratnesh Yadav started by attempting to develop a technology that could provide electrification at a village-wide level. After extensive research, biodiesel, wind, and solar were rejected on the basis that economics and supply chain issues would render each uneconomical. They were left with biomass, and the only form of unutilized biomass in Indian villages was rice husk. Pandey had heard of a plant in another state generating power from rice husks, though not entirely successfully. After observing and studying, the two designed a gasifier that could convert husk to a combustible gas and a generator to output electricity from the gas, resulting in a proprietary technology designed exclusively for the BoP and, more specifically, for the state of Bihar, where rice husk was abundant and unused. This technology has enormous potential using an untapped resource as an input and providing reliable electricity as an output (Shrimali, Dhanaraj, \& Sud, 2011).

The two founders were soon joined by two friends who specialized in business, thus rounding out the team. They developed a business model around the gasification technology and their target customers in underserved communities in Bihar. The founders matched the price of electricity to the poor "in relation to their ability to pay" (Jain \& Koch, 2009). Their target market was characterized by customers with uneven and extremely limited cash flows, and was matched with the payment plan associated with switching from kerosene: "Husk Power generates revenue by providing up to seven hours of electricity to villages in India at a cost that is less than one-fourth the monthly cost of kerosene lighting (\$2.00 v. \$8.00/month)" (Jain \& Koch, 2009). In addition to this revenue stream, HPS created additional sources of revenue from the sale 
of complementary electric appliance products, embodying the "longunderstood axiom in the expansion of access to electricity-supply creates its own demand" (Jain \& Koch, 2009). HPS also generates additional income by selling rice husk char which has additional value as a future carbon credit (Jain \& Koch, 2009). To lower costs even more, HPS also taps into Indian government subsidies for rural electrification which can cover up to $50 \%$ of a project's cost.

In addition to addressing the local economic context, HPS's model takes into account human capital issues as well, notably by creating its own training center in order to overcome the lack of skilled workers in Bihar and meet HPS's expected hiring requirements of 150-200 plant operators per year. HPS also builds community-level credibility by working through the local governance system (Jain \& Koch, 2009).

HPS's deliberate considerations of the local context led to a model which they believe can be readily adapted to all 125,000 un-electrified villages in India. The team recalled that the business plan "started looking like Starbucks-you can put one of these in 125,000 locations, hire local people, and turn a raw material into money-just substitute rice husks for coffee beans" (Shrimali et al., 2011).

Husk Power Systems is the epitome of frugal innovation-combining a technology that is both locally available and environmentally unobtrusive with a business model that provides low cost energy at a rate that mimics the income streams of the community it seeks to serve. HPS interfaces with its ecosystem in "textbook" fashion-it has established both external and internal credibility through prestigious awards and a village-level governance structure, built a training school to involve itself in upgrading community skill sets, and works with the government to receive subsidies in order to drive down cost. The incredible and oftenreferenced success of HPS can be attributed to the social enterprise's mastery of the three pillars of success at the BoP: appropriate technology, innovative business model, and interfacing with the local context.

\section{SECTION V: CONCLUSION}

The UN predicts that the population of the world's less developed regions will rise from 5.7 billion in 2011 to 8 billion in 2050, representing a 40\% increase (United Nations, 2011). Grid connectivity is not expected to keep pace with that growth, especially in Africa, so that by 2030 there will be 100 million more un-electrified people compared to 
today, and globally there will still be roughly 1.3 billion people without reliable electricity (Lighting Africa, 2010).

Based upon experience in the Global Social Benefit Incubator at Santa Clara University, it is believed that social enterprises can play a major role in providing necessary products and services to solve the energy related problems faced by these consumers. Doing so involves developing appropriate technologies, such as the SoLite3 Solar Home System from Angaza Design, finding a means to sell it in the context of deep poverty, like Solar Sister's Avon-style distribution network, and ensuring that both technology and business model interface with the local ecosystem so as to maximize impact, like Husk Power Systems. The interplay of these three factors leads to success in providing clean energy to the BoP. The lesson to those who aspire to have an impact in alleviating energy poverty at the BoP is this: listen to the consumers. Pay attention to local customs. Learn what people in the target underserved community need, what they value, and how they do business. It is an intimate knowledge and understanding of the user, the customer, and essentially the context of poverty that allows entrepreneurs to innovate in meaningful ways. The greater the degree that context is valued in conjunction with appropriate technologies and innovative business models, the more clean energy can be brought to those in need.

\section{REFERENCES}

Ballonoff, P. 2013. Providing access to electricity for the unserved: A free-market solution. Cato Journal, 33(1): 1-18.

Global Alliance for Clean Cookstoves. 2011. Igniting change: A strategy for universal adoption of clean cookstoves and fuels. Washington: Global Alliance for Clean Cookstoves.

Hystra. 2009. Access to energy for the base of the pyramid. Hystra 7-15, http:// www.hystra.com/opensource/HYSTRA_Access_to\%20_Energy.pdf (accessed November 8, 2012).

International Energy Agency. 2006. Energy for cooking in developing countries (2nd ed.). Paris: IEA Publications.

International Energy Agency. 2010. World energy outlook 2010. Paris: IEA Publications.

International Energy Agency. 2013. OECD, http://www.iea.org/topics/energypoverty/ (accessed March 22, 2013).

International Finance Corporation. 2012. From gap to opportunity: Business models for scaling up energy access. Washington: International Finance Corporation.

Jain, S., \& Koch, J. 2009. Social entrepreneurship in the provision of clean energy: Towards an organizing framework of market creation for 
underserved communities. Paper presented at the New York University Stern School of Business Conference on Social Entrepreneurship, New York.

Ki-Moon, B. 2011. Sustainable energy for all, http://www.sustainableenergyforall. org/about-us/item/download/40_1ea311a9f4d9afc3772cdf137bf25e09 (accessed March 5, 2013).

Koch, J., \& Hammond, A. 2013. Innovation dynamics, best practices, and trends in the off-grid clean energy market. The Journal of Management for Global Sustainability, 1(2): 121-139.

Kumar, N., \& Puranam, P. 2012. Frugal engineering: An emerging innovation paradigm. Ivey Business Journal, http://www.iveybusinessjournal.com/ topics/innovation/frugal-engineering-an-emerging-innovation-paradigm\#. UTcf96WmjpU (accessed March 5, 2013).

Lighting Africa. 2010. Solar lighting for the base of the pyramid: Overview of an emerging market, http://www1.ifc.org/wps/wcm/ connect/a68a120048fd175eb8dcbc849537832d/SolarLightingBasePyramid. pdf?MOD=AJPERES (accessed November 21, 2012).

Mlot, S. 2012. Infographic: Mobile use in developing nations skyrockets. PC, http:// www.pcmag.com/article2/0,2817,2407335,00.asp (accessed March 7, 2013).

Practical Action. 2012. Poor people's energy outlook 2012: Energy for earning a living. Rugby, United Kingdom: Practical Action Publishing.

Prahalad, C.K., \& Hammond, A. 2002. Serving the world's poor, profitably. Harvard Business Review, 80(9): 48-59.

Shrimali, G., Dhanaraj, C., \& Sud, K. 2011. Husk power systems. Richard Ivey School of Business. Draft case, Husk Power Systems. Ontario: Ivey Publishing.

Stevens, S. 2012. The seven deadly sins of social enterprise. Guardian.co.uk, December 13, 2012: http://socialenterprise.guardian.co.uk/social-enterprise-network/2012/ dec/13/seven-deadly-sins-social-enterprise (accessed March 12, 2013).

United Nations. 2011. World population prospects: The 2010 revision, volume I: Comprehensive tables. New York: United Nations.

World Bank. 2012. Mobile phone access reaches three quarters of planet's population. July 17: http://www.worldbank.org/en/news/press-release/2012/07/17/mobile-phoneaccess-reaches-three-quarters-planets-population (accessed March 10, 2013).

Yale School of Management. 2010. Design and social enterprise case series: Selco, http://nexus.som.yale.edu/design-selco/?q=node/99 (accessed March 3, 2013). 